\title{
Blood rheology and proliferative retinopathy in homozygous sickle cell disease
}

\author{
B E SERJEANT,' K P MASON,' R W ACHESON,' G H MAUDE,' J STUART, \\ AND G R SERJEANT
}

From the 'Medical Research Council Laboratories (Jamaica), University of the West Indies, Kingston, Jamaica, and the ${ }^{2}$ Department of Haematology, the Medical School, University of Birmingham, England

SUMmARY Some haematological and rheological features were compared in 27 age and sex matched pairs of patients (15 male, 12 female) with homozygous sickle cell (SS) disease with and without proliferative sickle retinopathy (PSR). Significant haematological differences between the groups were a higher haemoglobin and a lower fetal haemoglobin in PSR positive males and a higher MCHC in PSR positive females. The plasma viscosity and characteristics of erythrocyte filterability did not differ between those with and those without PSR, although PSR positive males had a significantly higher whole blood viscosity when measured at high shear and at the patient's own packed cell volume.

Although proliferative sickle retinopathy (PSR) is accepted as a sequel to vaso-occlusion in the peripheral retina in homozygous sickle cell (SS) disease, the factors which render only a minority of patients prone to this condition are largely unknown. An analysis of haematological differences between patients with SS disease with and without PSR' indicated that patients with a combination of high haemoglobin levels and low fetal haemoglobin ( $\mathrm{HbF})$ levels were at greatest risk. Age is also important, the frequency of PSR rising with age after 10 years and the complication being especially prone to develop between the ages of 15 and 29 years. ${ }^{2} \mathrm{~A}$ further factor complicating the assessment of risk factors for PSR is the frequency of autoinfarction, which may abort the pathological process of PSR. ${ }^{3}$

Since important risk factors for PSR must reside in the haematological abnormalities of patients with SS disease, some characteristics of blood viscosity and of erythrocyte deformability have been studied in age and sex matched groups of patients with and without PSR.

\section{Materials and methods}

The patients were drawn from the Sickle Cell Clinic of the University Hospital of the West Indies and

Correspondence to Graham R Serjeant, Medical Research Council Laboratories (Jamaica), University of the West Indies, Kingston 7, Jamaica. from a group of peripheral sickle cell clinics all operated by the staff of the Medical Research Council (MRC) Laboratories. There were 27 patients (15 male) with PSR who were each matched with a patient of the same sex and similar age in whom retinal examination within the last year had confirmed the absence of PSR. Where possible the viscosity studies were performed on patients and controls on the same day. Ages ranged from 21 to 54 years (patients) and from 21 to 56 years (controls), with a mean age of 37.2 years in the PSR group and 38.1 years in the controls. Since homozygous $\alpha$ thalassaemia 2 is known to influence blood rheology, ${ }^{4}$ patients with this genetic subdivision of SS disease were avoided in all but one female index case.

The criteria for the diagnosis of SS disease ${ }^{5}$ and the techniques of ocular examination ${ }^{6}$ were as previously described. Plasma fibrinogen was measured by the clot weight method. ${ }^{7}$ Blood viscosity was measured at $25^{\circ} \mathrm{C}$ and high $\left(230 \mathrm{~s}^{-1}\right)$ shear rate in a Wells-Brookfield microviscometer and plasma viscosity at $25^{\circ} \mathrm{C}$ in a Coulter-Harkness capillary viscometer, as decribed elsewhere. ${ }^{4}$ Each patient's blood was adjusted by removing or adding plasma to give three samples of different packed cell volume (range $0 \cdot 30-0 \cdot 40$ ). A regression line of log viscosity against packed cell volume (PCV) for the three samples was drawn, so that viscosity values corresponding to the patient's original PCV and to a standard value of 0.45 could be calculated. ${ }^{4}$ Erythrocyte deformability (filterability) 
was measured at ambient temperature by a positive pressure, constant flow system using $5 \mu \mathrm{m}$ pore diameter polycarbonate membranes (Nucleopore Corporation, Pleasanton, USA), as previously described. ${ }^{4}$ The characteristics of the time-pressure curves were analysed ${ }^{8}$ into four components, the initial pressure $(\mathrm{Pi})$, the final pressure $(\mathrm{Pf})$, the initial steep slope (slope 1) representing the rise in pressure as the erythrocytes encountered the filter and a second more gradual slope (slope 2) representing the increment in pressure necessary to maintain filtration. All four parameters were strongly correlated and, as previously, ${ }^{8} \mathrm{Pi}$ and slope 2 were arbitrarily selected to define the characteristics of the curve.

Statistical analysis was by Student's $t$ test for matched pairs and by multiple logistic regression. ${ }^{9}$ Variables with skewed distributions (reticulocytes, $\mathrm{HbF}$, fibrinogen, and slope 2) were transformed as follows: $\log _{e}$ (reticulocytes +1$), \log _{e}(\mathrm{HbF}+1), \log _{\mathrm{e}}$ (fibrinogen), and $\log _{e}$ (slope $2+1$ ) to provide approximately normal distributions.

\section{Results}

Some haematological features in the PSR and nonPSR groups are presented for male and female patients in Tables 1 and 2 respectively. Male patients with PSR had significantly lower $\mathrm{HbF}$ and significantly higher haemoglobin and packed cell volume than males without PSR, as previously noted.' No such difference was apparent in female patients, though a significantly higher mean corpuscular haemoglobin concentration (MCHC) occurred in the PSR group.

The viscosity and erythrocyte filterability results for the two sexes are summarised in Tables 3 and 4 respectively. Whole blood viscosity, when measured at each patient's own packed cell volume, was significantly higher in PSR positive males, this effect probably being attributable to the haemoglobin level, since multiple logistic regression analysis indicated no effect independent of haemoglobin and $\mathrm{HbF}$ levels. No differences were apparent between PSR and non-PSR groups in females. Plasma viscosity and erythrocyte filterability were not significantly different for either sex between patients with or without PSR.

\section{Discussion}

The only significant difference in rheological indices between PSR and non-PSR groups was an increase in

Table 1 Some haematological features of the PSR and non-PSR groups in males

\begin{tabular}{|c|c|c|c|c|c|c|}
\hline \multirow[t]{2}{*}{ Variable } & \multicolumn{2}{|l|}{$P S R+v e$} & \multicolumn{2}{|l|}{$P S R-v e$} & \multicolumn{2}{|c|}{ Significance of difference } \\
\hline & Mean & $S D$ & Mean & $S D$ & $t$ & $p$ \\
\hline $\log _{c}(\mathrm{HbF}+1)$ & $1 \cdot 11(3 \cdot 1)$ & 0.62 & $1 \cdot 60(4 \cdot 0)$ & $0 \cdot 61$ & $-2 \cdot 18$ & $<0.05$ \\
\hline $\mathrm{Hb}(\mathrm{g} / \mathrm{dl})$ & $8 \cdot 9$ & 0.9 & $7 \cdot 9$ & 0.9 & $2 \cdot 89$ & $<0.05$ \\
\hline $\operatorname{PCV}(1 / 1)$ & $0 \cdot 268$ & 0.032 & $0 \cdot 237$ & 0.027 & $2 \cdot 80$ & $<0.05$ \\
\hline $\mathrm{MCHC}(\mathrm{g} / \mathrm{dl})$ & $33 \cdot 2$ & 1.9 & $33 \cdot 4$ & $2 \cdot 6$ & $-0 \cdot 30$ & NS \\
\hline $\operatorname{MCV}(f 1)$ & $88 \cdot 5$ & $7 \cdot 7$ & $90 \cdot 3$ & $13 \cdot 3$ & -0.49 & NS \\
\hline $\mathrm{MCH}(\mathrm{pg})$ & $29 \cdot 4$ & $2 \cdot 7$ & $30 \cdot 8$ & 4.9 & $-1 \cdot 02$ & NS \\
\hline $\log _{c}($ reticulocytes +1$)$ & $2.44(10 \cdot 5)$ & $0 \cdot 29$ & $2 \cdot 41(10 \cdot 2)$ & 0.39 & 0.01 & NS \\
\hline $\log _{c}($ fibrinogen $)$ & $1 \cdot 25(3 \cdot 3)$ & 0.48 & $1 \cdot 18(3 \cdot 3)$ & $0 \cdot 30$ & 0.62 & NS \\
\hline
\end{tabular}

$t$ Test based on 15 matched pairs. NS=not significant. Figures in parentheses represent mean values re-expressed in original units.

Table 2 Some haematological features of the PSR and non-PSR groups in females

\begin{tabular}{|c|c|c|c|c|c|c|}
\hline \multirow[t]{2}{*}{ Variable } & \multicolumn{2}{|l|}{$P S R+v e$} & \multicolumn{2}{|l|}{$P S R-v e$} & \multicolumn{2}{|c|}{ Significance of difference } \\
\hline & Mean & $S D$ & Mean & $S D$ & $t$ & $p$ \\
\hline $\log _{c}(\mathrm{HbF}+1)$ & $1 \cdot 81(5 \cdot 1)$ & 0.67 & $1 \cdot 86(5.4)$ & $0 \cdot 79$ & $-0 \cdot 15$ & NS \\
\hline $\mathrm{Hb}(\mathrm{g} / \mathrm{dl})$ & $7 \cdot 7$ & $1 \cdot 3$ & $7 \cdot 7$ & $1 \cdot 1$ & $-0 \cdot 04$ & NS \\
\hline $\operatorname{PCV}(1 / 1)$ & $0 \cdot 228$ & 0.037 & $0 \cdot 241$ & 0.033 & -0.91 & NS \\
\hline $\mathrm{MCHC}(\mathrm{g} / \mathrm{dl})$ & $33 \cdot 6$ & 1.9 & $31 \cdot 8$ & $1 \cdot 5$ & $2 \cdot 24$ & $\mathrm{p}<0.05$ \\
\hline $\mathrm{MCH}(\mathrm{pg})$ & 29.9 & $3 \cdot 3$ & $30 \cdot 2$ & $2 \cdot 9$ & $-0 \cdot 25$ & NS \\
\hline $\log _{c}($ reticulocytes +1$)$ & $2 \cdot 21(8 \cdot 2)$ & 0.44 & $2 \cdot 35(9 \cdot 5)$ & 0.42 & -0.63 & NS \\
\hline $\log _{c}($ fibrinogen $)$ & $1 \cdot 24(3 \cdot 5)$ & $0 \cdot 26$ & $1 \cdot 23(3 \cdot 4)$ & $0 \cdot 22$ & 0.07 & NS \\
\hline
\end{tabular}

$t$ Test based on 12 matched pairs. NS=not significant. Figures in parentheses represent mean values re-expressed in original units. 
the male PSR group of whole blood viscosity measured at the patient's own packed cell volume. At the given shear rate $\left(230 \mathrm{~s}^{-1}\right)$, viscosity measurements reflect erythrocyte deformability, since interactions between cells (for example, rouleaux) are prevented. The observation that significant differences emerged at the patient's packed cell volume but not when expressed at a standard packed cell volume $(0 \cdot 45)$ implies that the haemoglobin level in individual patients may be important.

Previous analyses of the haematological determinants of $\mathrm{PSR}^{1}$ have indicated important sex differences, male patients with PSR having significantly higher haemoglobin and lower fetal haemoglobin (HbF) levels but no relationship being apparent in female patients. A similar pattern occurred in the present study, and in addition female PSR patients had a significantly raised $\mathrm{MCHC}$.

The results of the present study were therefore consistent with previous findings in the haematological features and have added the observation of a significant difference in whole blood viscosity in males when measured at each patient's own packed cell volume. An apparent negative finding has been that erythrocyte deformability, as measured by the positive filtration technique, does not appear to differ between PSR and non-PSR groups. The presence of contaminating leucocytes in our test erythrocyte suspensions may have reduced the sensitivity of the method to alterations in erythrocyte deformability."' Thus high-shear viscosity measurements in this study were probably a truer reflection of erythrocyte deformability, and future filtration studies should employ a leucocyte depleted (to $<0 \cdot 025 \times 10^{9} / \mathrm{l}$ leucocytes) erythrocyte suspension." Such studies are required to confirm whether haematocrit alone, as suggested in the present study, is the cause of hyperviscosity in males with PSR or whether a reduction in erythrocyte deformability is an additional factor.

There are additional problems in using these methods to determine the risk factors associated with the development of PSR. In most cases patients are being studied years after the development of PSR, and their current haematological and viscosity characteristics may not accurately reflect those at the time of development of PSR. Furthermore the group developing PSR may not be those with the greatest vaso-occlusive tendency, since, in these, occlusion of the abnormal arteriovenous communications that precede PSR may actually inhibit its development. Such a situation would differ from the well recognised

Table 3 Comparison of viscosity and red cell filterability in PSR and non-PSR groups in males

\begin{tabular}{|c|c|c|c|c|c|c|}
\hline \multirow[t]{2}{*}{ Variable } & \multicolumn{2}{|l|}{$P S R+v e$} & \multicolumn{2}{|l|}{$P S R-v e$} & \multicolumn{2}{|c|}{ Significance of difference } \\
\hline & Mean & $S D$ & Mean & $S D$ & $t$ & $p$ \\
\hline \multicolumn{7}{|l|}{ Viscosity } \\
\hline Plasma (mPas) & $1 \cdot 83$ & $0 \cdot 20$ & $1 \cdot 82$ & $0 \cdot 14$ & $0 \cdot 19$ & NS \\
\hline Whole blood (own PCV)* & $4 \cdot 46$ & $0 \cdot 70$ & $3 \cdot 89$ & 0.41 & $2 \cdot 71$ & $<0.05$ \\
\hline Whole blood $(\mathrm{PCV}=0.45)$ & $8 \cdot 35$ & $2 \cdot 37$ & $7 \cdot 37$ & $1 \cdot 17$ & $1 \cdot 45$ & NS \\
\hline \multicolumn{7}{|l|}{ Erythrocyte filterability } \\
\hline $\mathrm{Pi}(\mathrm{mmHg})$ & $15 \cdot 7$ & $2 \cdot 6$ & $17 \cdot 4$ & $5 \cdot 9$ & -0.99 & NS \\
\hline $\log _{c}($ slope $2+1)$ & $0.99(1.7)$ & $0 \cdot 37$ & $1 \cdot 16(2 \cdot 2)$ & 0.34 & $-1 \cdot 39$ & NS \\
\hline
\end{tabular}

$t$ Test based on 15 pairs except ${ }^{*}$ when calculated from 14 pairs with complete data. Figures in parentheses represent mean values re-expressed in original units.

Table 4 Comparison of viscosity and red cell filterability in PSR and non-PSR groups in females

\begin{tabular}{|c|c|c|c|c|c|c|}
\hline \multirow[t]{2}{*}{ Variable } & \multicolumn{2}{|l|}{$P S R+v e$} & \multicolumn{2}{|l|}{$P S R-v e$} & \multicolumn{2}{|c|}{ Significance of difference } \\
\hline & Mean & $S D$ & Mean & $S D$ & $t$ & $p$ \\
\hline \multicolumn{7}{|l|}{ Viscosity } \\
\hline Plasma (mPas) & $1 \cdot 83$ & $0 \cdot 16$ & $1 \cdot 79$ & $0 \cdot 11$ & $1 \cdot 02$ & NS \\
\hline Whole blood (own PCV) & 3.95 & $0 \cdot 34$ & $3 \cdot 81$ & 0.75 & 0.64 & NS \\
\hline Whole blood $(\mathrm{PCV}=0.45)$ & $7 \cdot 39$ & $1 \cdot 02$ & $7 \cdot 41$ & $1 \cdot 63$ & -0.04 & NS \\
\hline \multicolumn{7}{|l|}{ Erythrocyte filterability } \\
\hline $\mathrm{Pi}(\mathrm{mmHg})$ & $16 \cdot 6$ & $3 \cdot 8$ & $16 \cdot 4$ & $3 \cdot 1$ & 0.09 & NS \\
\hline $\log _{c}($ slope $2+1)$ & $1 \cdot 05(1.9)$ & $0 \cdot 29$ & $0 \cdot 84(1 \cdot 3)$ & 0.26 & $1 \cdot 64$ & NS \\
\hline
\end{tabular}

$t$ Test based on 12 matched pairs. Figures in parentheses represent mean values re-expressed in original units. 
autoinfarction of established PSR, ${ }^{3}$ since PSR would not occur.

A reasonable working hypothesis for the development of PSR in sickle cell disease would recognise three groups of patients according to their vasoocclusive tendency. Patients with the lowest vasoocclusive tendency would not develop peripheral retinal vaso-occlusion and retinal infarction. Patients with intermediate indices would develop such occlusion and infarction, and abnormal arteriovenous communications would form at the junction of vascular and avascular retina from which the lesion of PSR would develop. Patients with the highest vasoocclusive indices would develop retinal infarction but would also have occlusion of the abnormal arteriovenous communications, which would inhibit the development of PSR.

Such a hypothesis could explain the unexpected observations that the prevalence of PSR is highest in sickle cell-haemoglobin C (SC) disease and in sickle cell- $\beta^{+}$thalassaemia, which are generally mild conditions associated with less evidence of vaso-occlusion. This hypothesis could also explain the lack of more dramatic differences between PSR and non-PSR groups in the present study, since, whereas the PSR group would represent those with moderate vasoocclusive tendencies, the non-PSR control group may represent a mixture of those with high and low vaso-occlusive tedencies.

Testing this hypothesis requires an accurate method of assessing the vaso-occlusive tendency in an individual, and this must await a better understanding of the pathological mechanisms in sickle cell disease. Factors likely to affect this are the size, shape, density, number, and deformability of erythrocytes, the haemodynamic adaptations to anaemia, the nature of vessel walls, interactions between erythro- cytes and endothelial cells, and possible contributions from other formed elements such as platelets and leucocytes. Studies of these individual components in groups of patients with and without PSR may contribute to this understanding. The present study has demonstrated the importance of haematocrit as a determinant of the raised whole blood viscosity in males with PSR.

This work was supported in part by National Institutes of Health grant HL 15168 and by the Welcome Trust.

\section{References}

1 Hayes RJ, Condon PI, Serjeant GR. Hacmatological factors associated with proliferative retinopathy in homozygous sickle cell disease. Br J Ophthalmol 1981; 65: 29-35.

2 Condon PI, Hayes RJ, Serjeant GR. Retinal and choroidal neovascularization in sickle cell disease. Trans Ophthalmol Soc UK 1980; 100: 434-9.

3 Condon PI, Serjeant GR. Behaviour of untreated proliferative sickle retinopathy. Br J Ophthalmol 1980; 64: 404-11.

4 Serjeant BE, Mason KP, Kenny MW, et al. Effect of alpha thalassaemia on the rheology of homozygous sickle cell diseasc. Br J Haematol 1983; 55: 479-86.

5 Serjeant GR. The clinical features of sickle cell disease. Amsterdam: North Holland, 1974.

6 Condon PI, Serjeant GR. Ocular findings in homozygous sickle cell anemia in Jamaica. Am J Ophthalmol 1972; 73: 533-43.

7 Ingram GIC. A suggested schedule for the rapid investigation of acutc haemostatic failure. J Clin Pathol 1961; 14: 356-60.

8 Serjeant BE, Mason KP, Condon PI, et al. Blood rheology and proliferative retinopathy in sickle cell-haemoglobin C disease. $\mathrm{Br}$ J Ophthalmol 1984; 68: 325-8.

9 Nelder JA, Wedderburn RWM. Generalised linear models. $J R$ Statist Soc (A) 1972; 135: 370-84.

10 Kenny MW, Meakin M, Stuart J. Methods for removal of leucocytes and platelets prior to study of erythrocyte deformability. Clin Hemorheol 1983; 3: 191-200.

11 Stuart J, Stone PCW, Bareford D, Caldwell NM, Davies JE, Baar S. Evaluation of leucocyte removal methods for studies of erythrocyte deformability. Clin Hemorheol 1985; 5: 137-47.

Accepted for publication 7 November 1985. 